\title{
The Determination of Negative Voltage during Magnesium Alloy Plasma Process
}

\author{
Xi-Zhi JIANG ${ }^{1, a}$, Yong-Fu ZHAO ${ }^{1, b,{ }^{*}}$ \\ ${ }^{1}$ The Institute for Agricultural Facilities and Equipment, Jiangsu Academy of Agricultural Sciences, \\ Nanjing, 210014, Jiangsu, China \\ apinzhongsheng@163.com, byfzyf2002@163.com \\ ${ }^{*}$ Corresponding author
}

Keywords: Magnesium Alloy, Micro-arc Oxidation, Negative Voltage, Steps Increasing.

\begin{abstract}
Plasma process was carried out on ZK60 Mg alloy to explore the effects of different negative voltage on the characteristics of coatings. Surface and cross-section morphologies, coating thickness and corrosion resistance of coatings were investigated by scanning electron microscopy (SEM), energy disperse spectroscopy (EDS), microscope with super-depth of field and electrochemical impedance spectroscopy (EIS). The results reveal that the coating formed under two steps increasing negative voltage mode of $20-25 \mathrm{~V}$ is superior to that formed under other negative modes. It is of help to develop a compact, smooth, thick MAO coating. The corresponding coating with maximum thickness of about $16.959 \mu \mathrm{m}$ exhibited the best corrosion resistance with high electrochemical impedance of $2.565 \times 10^{10} \mathrm{ohm} . \mathrm{cm}^{2}$ which is higher than that of substrate about 5 orders of magnitude and low corrosion rate of $0.748 \mathrm{~g} / \mathrm{m}^{2} \mathrm{~h}$.
\end{abstract}

\section{Introduction}

It is known that magnesium alloy with low density, high strength ratio, good electromagnetic shielding property, as well as good machining and recycling ability [1-4], is more widely used in many fields[5,6] after the improvement of its corrosion resistance[7-9] by plasma surface treatment[10-12].

Micro-arc oxidation(MAO), a relatively new plasma method, can produce a thick and dense coating[2,13].The traditional researches of MAO were mainly about the concentration and chemical composition of electrolyte [14-16] and electric parameters [17-20] including current density, voltage, duty ratio and frequency in a constant mode.

However, the majority of them used a single constant electrical parameter mode. A new way of two steps negative voltage-increasing mode in this paper was put forward to produce better characteristic MAO coatings [21]. Based on the previous work, the effects of negative voltage on MAO coating were investigated by means of the comparison of constant negative voltage mode and two steps increasing mode in this research.

\section{Experimental}

Rectangular coupons $(20 \mathrm{~mm} \times 20 \mathrm{~mm} \times 5 \mathrm{~mm})$ of ZK60 magnesium alloy $(\mathrm{Zn} \mathrm{4.8-6.2,} \mathrm{Zr}>0.45$, impurities $\leqq 0.30, \mathrm{Mg}$ balance) were prepared by means of electric arc CNC wire-cut machine and polished with alumina waterproof abrasive paper up to 1200 grits. And then the coupons were cleaned in an ultrasonic bath with acetone and ethyl alcohol respectively at room temperature for 10 min prior to MAO process.

WHD-20 MAO system was employed in MAO experiments. The dual electrolytes system was prepared from distilled water containing $14 \mathrm{~g} / \mathrm{L} \mathrm{NaAlO}{ }_{2}, 6 \mathrm{~g} / \mathrm{L} \mathrm{Na} \mathrm{PO}_{4}, 4 \mathrm{~g} / \mathrm{L} \mathrm{NaOH}, 3 \mathrm{~g} / \mathrm{L} \mathrm{NaB} \mathrm{N}_{7}$, and $4 \mathrm{~g} / \mathrm{L} \mathrm{C}_{6} \mathrm{H}_{5} \mathrm{Na}_{3} \mathrm{O}_{7}[22]$. The experiments were carried out under two steps voltage-increasing mode of $280-360 \mathrm{~V}$ by controlling different duty cycle and frequency while the other electric parameters including negative voltage and oxidation time kept constant with the value of $20 \mathrm{~V}$ and $15 \mathrm{~min}$ 
respectively. All MAO experiments were conducted at an electrolyte temperature of less than $35{ }^{\circ} \mathrm{C}$ and the current-time curves were recorded automatically during MAO process.

In the experiment, negative voltage could be regulated on line during MAO process to achieve the increasing of voltage by two steps. The constant negative voltages were as follows respectively: $15 \mathrm{~V}$, $20 \mathrm{~V}, 25 \mathrm{~V}$. And then two steps negative voltage-increasing mode was carried out. One adjusting method of $15 \mathrm{~V}(0-180 \mathrm{~s})-20 \mathrm{~V}(180-600 \mathrm{~s})$ : the first step was required for $180 \mathrm{~s}$ with the initial negative voltage value of $15 \mathrm{~V}$, while the second step was applied with the value of $20 \mathrm{~V}$ for the rest $420 \mathrm{~s}$. Another adjusting method of $20 \mathrm{~V}(0-180 \mathrm{~s})-25 \mathrm{~V}(180-600 \mathrm{~s})$ : the first step was required for 180s with the initial negative voltage value of $20 \mathrm{~V}$, while the second step was applied with the value of $25 \mathrm{~V}$ for the rest 420 s.

The coating microstructures and thickness were investigated by JSM-6480 SEM and Keyence VHX-900 digital microscope. Test of mass loss and electrochemical impedance spectroscopy were conducted at a $3.5 \% \mathrm{NaCl}$ solution to assess the resistance of coating to corrosion.

\section{Results and Discussion}

\section{Coating Thickness}

For coating thickness and corrosion rate with different negative voltage, as shown in Fig.1, the thickness of MAO coatings increases with increased value of constant negative voltage, it is the same with corrosion resistance. This is because higher negative voltage led to higher negative current. It makes the role of a long time and the fully charge and discharge process. The formation process of coatings is more stable. So the smaller discharge channel was conducive to the growth of film thickness and to improve the corrosion resistance of film [23].

When negative voltage is $15 \mathrm{~V}$, the coating is $10.850 \mathrm{um}$ in thickness, and characterized with a high corrosion rate $\left(1.108 \mathrm{~g} / \mathrm{m}^{2} \mathrm{~h}\right)$. For negative voltage $25 \mathrm{~V}$, the maximum coating thickness is $16.837 \mathrm{um}$ corresponding to a lower corrosion rate of $0.742 \mathrm{~g} / \mathrm{m}^{2} \mathrm{~h}$. It might be attributed to the maximum negative voltage which provided enough breakdown driving force and formed a compact coating.

When two steps negative voltage-increasing mode $20-25 \mathrm{~V}$, the coating is the thickest (16.959um) and more corrosive $\left(0.748 \mathrm{~g} / \mathrm{m}^{2} \mathrm{~h}\right)$. The energy consumption of $20-25 \mathrm{~V}$ is lower than that of constant negative voltage $25 \mathrm{~V}$. It is show that two steps increasing mode can make a better performance coating. When a negative voltage was applied, the sample was in a cathode state sometimes, then the water was electrolyzed to generate hydrogen gas at the surface layer of the samples. Bigger negative voltage would increase the carrier density of positive current, so that the reaction to proceed is more smoothly $[24,25]$.

\section{Corrosion Resistance}

The result of electrochemical impedance spectroscopy (EIS) of MAO coatings with different negative voltage is shown in Fig.2. The value of low frequency impedance first increases and then decreases with increased value of constant negative voltage. It is supposed that higher value of low frequency impedance of the coating will show better corrosion resistance. It could be seen from Fig.2, the highest value of low frequency impedance of constant negative voltage $20 \mathrm{~V}$ is $4.887 \times 10^{9}$ $\mathrm{ohm} . \mathrm{cm}^{2}$, which increases by 4 orders of magnitude compared to the lowest value of low frequency impedance $\left(1.564 \times 10^{5} \mathrm{ohm} . \mathrm{cm}^{2}\right.$ of $\left.15 \mathrm{~V}\right)$. Although the value of low frequency impedance of constant negative voltage $25 \mathrm{~V}$ is only $3.186 \times 10^{6} \mathrm{ohm} . \mathrm{cm}^{2}$, showing great corrosion tendency on the surface, but it done not reflect the corrosion rate really [26]. Therefore, low impedance value and low corrosion rate were not contradictory.

When two steps negative voltage-increasing mode $20-25 \mathrm{~V}$, the value of low frequency impedance is $2.565 \times 10^{10} \mathrm{ohm} . \mathrm{cm}^{2}$, which increases by 1 order of magnitude compared to the highest impedance value of constant negative voltage $20 \mathrm{~V}\left(4.887 \times 10^{9} \mathrm{ohm} . \mathrm{cm}^{2}\right)$. The thicker and more compact coating shown the best corrosion resistant, which is completely consistent with the result of corrosion rate. 

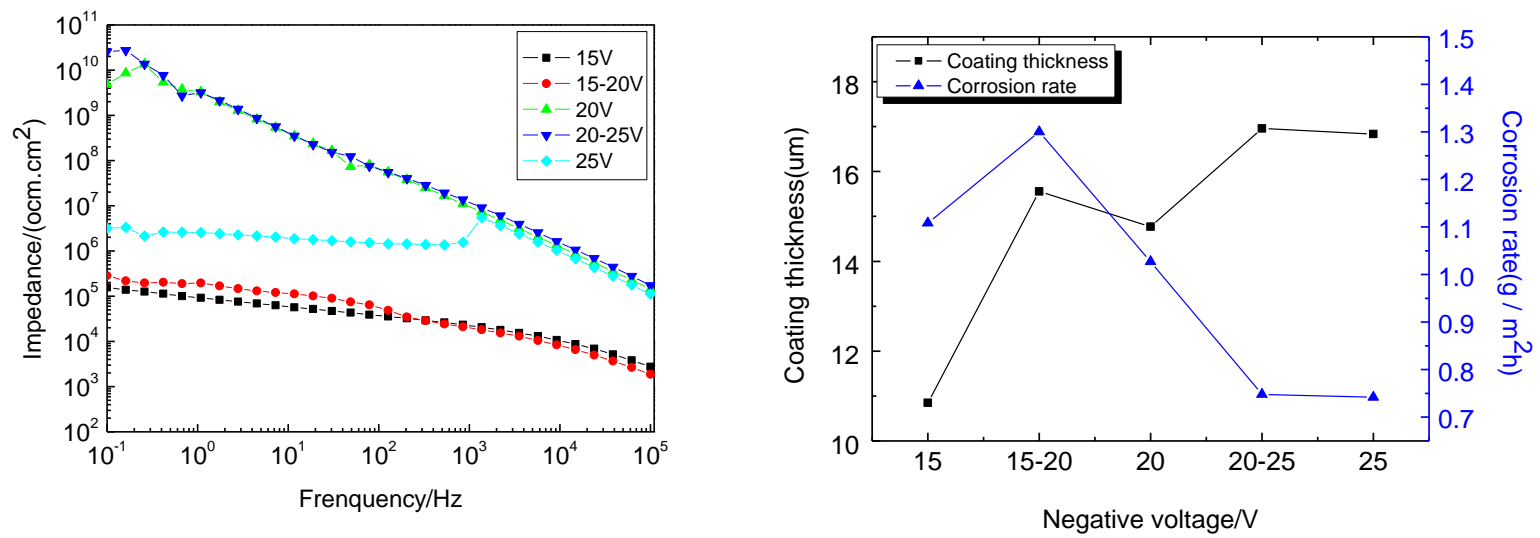

Fig.1 Coating thickness and corrosion rate with Fig. 2 EIS (Bode) in $3.5 \% \mathrm{NaCl}$ solution for MAO different negative voltage coating with different negative voltage

\section{MAO Coating Morphology}

Surface morphologies of MAO coatings under different negative voltage are presented in Fig.3, the mode $20 \mathrm{~V}, 20 \mathrm{~V}-25 \mathrm{~V}$ and $25 \mathrm{~V}$ of good corrosion resistance as an example. It shows that the surface morphology of two steps negative voltage-increasing mode $20-25 \mathrm{~V}$ is superior to the surface morphology of constant negative voltage. Compare figure (a), (b), (c), when the constant negative voltages are $20 \mathrm{~V}$ and $25 \mathrm{~V}$, the surface of the coatings is characterized with large pores and micro-cracks, as shown in figure (a) and (c). Porosity is larger, individual aperture is up to $3.3 \mathrm{um}$. The surface of films is roughness and loose.

However, the surface morphology of the coating under two steps negative voltage-increasing mode $20-25 \mathrm{~V}$ is smooth, less number of pores and uniform distribution. Pore size is small. The average pore diameter is about $1.09 \mathrm{um}$. The surface with little melts shows better quality.
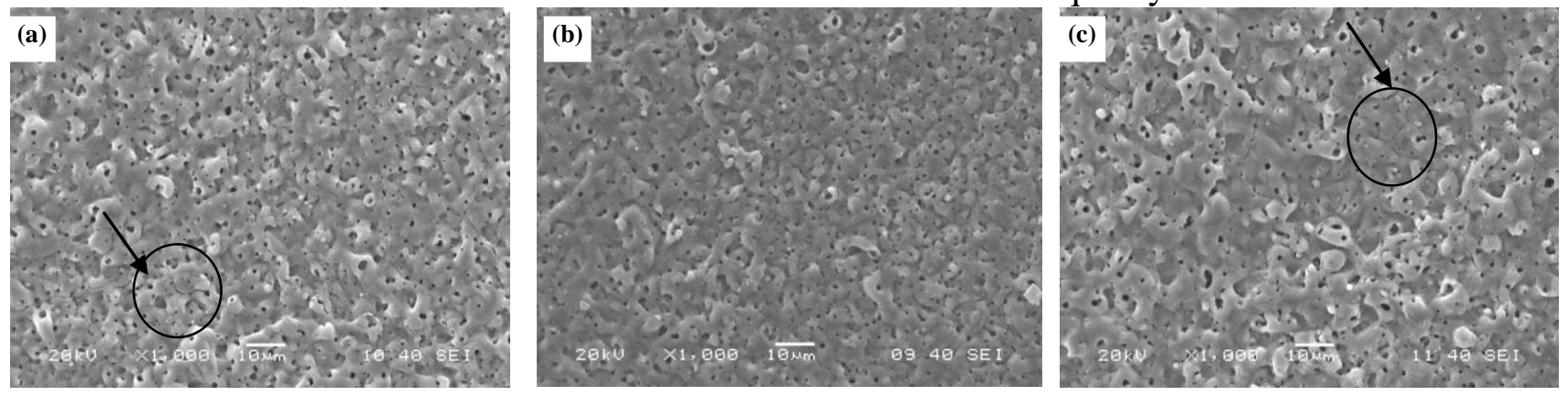

Fig.3 Surface morphologies of coatings: (a) 20V; (b) 20V-25V; (c) $25 \mathrm{~V}$

Cross-section morphologies of MAO coatings under different negative voltage are presented in Fig.4, the mode $20 \mathrm{~V}-25 \mathrm{~V}$ and $25 \mathrm{~V}$ of about the same thickness as an example. Compare figure (a), (b), two steps negative voltage-increasing mode $20-25 \mathrm{~V}$ with uniform and compact structure cross-section morphology, is better than that of constant negative voltage 25V. As shown in Fig.4(b), the arrow indicates loose material on the surface obviously and the ups and downs of concave and convex surface coating. As shown in Fig.4(a), the outer layer surface is smooth and the interface of inner surface and the substrate is flat relatively. It shows that the inward and outward growth morphologies of the film are ideal, and the rate is basically the same.

On the basis of the above analysis, it is considered that two steps increasing mode can make the negative voltage of micro-arc oxidation periodic increase. It is conducive to smooth transition growth of the coating. The first stage of low voltage can meet the discharge requirements and reduce the energy consumption. After the first stage, the film thickness reaches a certain value and has a certain breakdown resistance. The second stage with a larger negative voltage, the breakdown strength of the film increases and provides enough reaction driving force. Thus, coating breakdown grows again. 
Comprehensive evaluation, the coating of two steps increasing mode $20-25 \mathrm{~V}$ is even, flat, small pore size and good surface morphology.
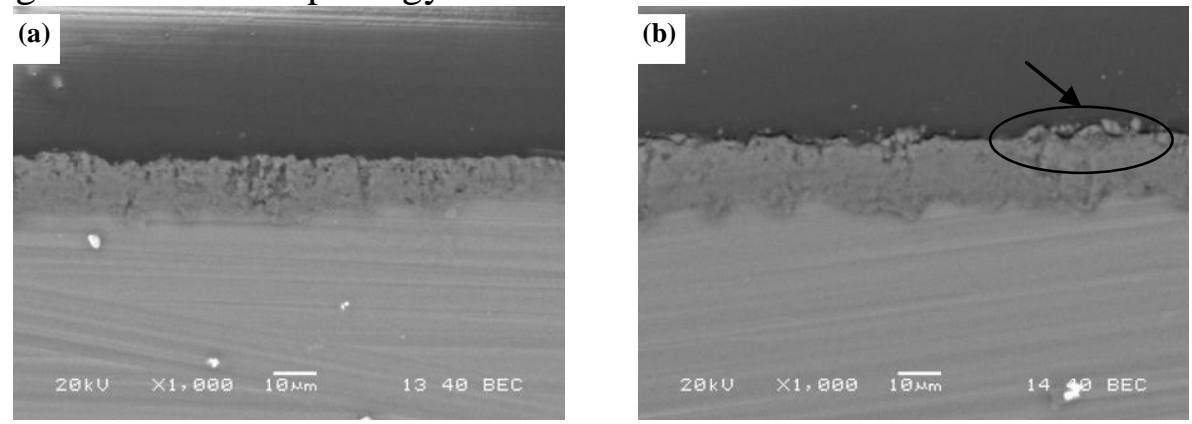

Fig.4 Cross-section morphologies of coatings: (a) 20V-25V; (b) $25 \mathrm{~V}$

\section{Coating Evolution with Negative Voltage}

Current-time curves of coating under the optimized mode 20-25V is shown in Fig.5. The first stage $(0-180 \mathrm{~s})$, positive voltage is $280 \mathrm{~V}$, negative voltage is $20 \mathrm{~V}$. At this stage, the trend of positive current and negative current is the same basically. The current rises rapidly. The peak of positive current is 6.8A. The peak of negative current is 3.4A. And then the current declines slowly. The difference is that positive current starts from the beginning, while the negative current delays of about 20s.

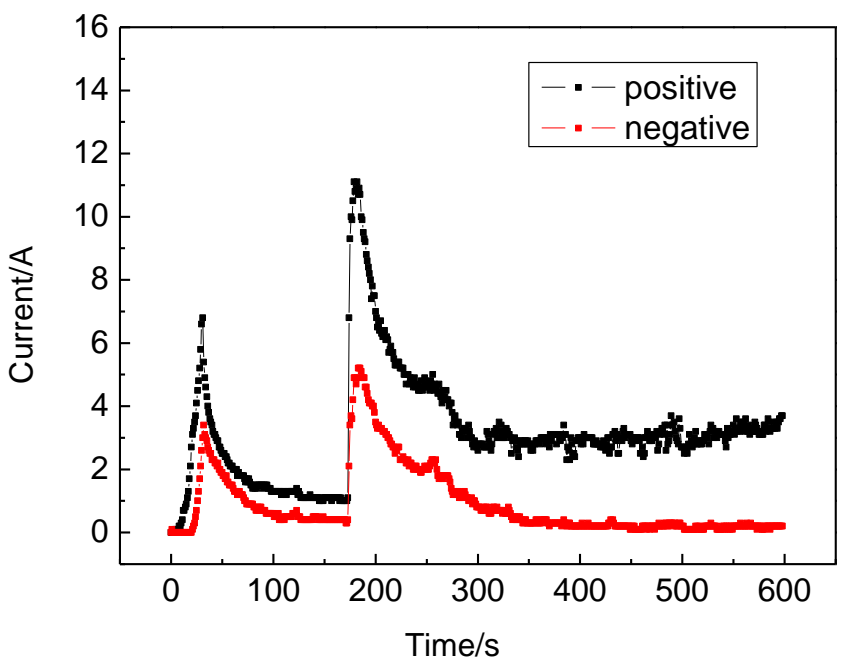

Fig.5 Current-time curves of coatings: 20V-25V

The second stage (180-600s), positive voltage is $360 \mathrm{~V}$, negative voltage is $25 \mathrm{~V}$. There is a rapid current- increasing and then a slower current-decreasing process which compares to current evolution at the first stages. The peak of positive current is $11.1 \mathrm{~A}$. The peak of negative current is 5.2A. Both of them higher than the first stage significantly. When the current reaches the maximum value, it begins to decline, but it decreases slower than the first stage. So micro-arc oxidation reaction time was significantly prolonged. The result showed that the increase of negative voltage was conducive to the growth of coating. It is get a thick film. After the first stage, the film had a certain breakdown resistance. Positive voltage and negative voltage increased greatly at the second stage and the breakdown reaction driving force was much more enough. So the peak currents were higher than that of first stage. It would be helpful for growth of film breakdown again. The positive current in later period of micro-arc oxidation appeared obvious resilience rise. It presented partial discharge test at the button and the ablation phenomenon in later period of micro-arc oxidation during the process of experiment, which might have influence on the corrosion resistance of coating. 


\section{Summary}

By means of singles variable experiment, optimized electric parameters were developed with different negative voltage mode. It shows that a relatively long main MAO period of current-time with higher current peak is helpful for producing the coating. Negative voltage of $20-25 \mathrm{~V}$ can form a thick and compact coating with good corrosion resistance of high electrochemical impedance of $2.565 \times 10^{10} \mathrm{ohm} . \mathrm{cm}^{2}$.

\section{Acknowledgment}

The present work was supported by a project funded by the Key Laboratory of Advanced Welding Technology of Jiangsu Province, P. R. C, grant No. JSAWT - 11- 08.

\section{References}

[1]S.V. Gnedenkov, O.A. Khrisanfova, A.G. Zavidnaya, PEO coatings obtained on an Mg-Mn type alloy under unipolar and bipolar modes in silicate-containing electrolytes, Surface and Coatings Technology. 204 (2010) 2316-2322.

[2]L.R. Chang, F.H. Cao, J.S. Cai, Influence of electric parameters on MAO of AZ91D magnesium alloy using alternative square-wave-power source, Trans. Nonferrous Met. Soc. China. 21 (2011) 307-316.

[3]J. Liang, L. Hu, J. Hao, Characterization of microarc oxidation coatings formed on AM60B magnesium alloy in silicate and phosphate electrolytes, Appl. Surf. Sci. 253 (2007) 4490-4496.

[4]Y.K. Lee, K. Lee, T. Jung, Study on microarc oxidation of AZ31B magnesium alloy in alkaline metal silicate solution, Electrochem. Commun. 10 (2008) 1716-1719.

[5]X.P. Zhang, Z.P. Zhao, F.M. Wu, Corrosion and wear resistance of AZ91D magnesium alloy with and without microarc oxidation coating in Hank's solution, J. Mater. Sci. 42 (2007) 8523-8528.

[6]D.Salih, U.Metin, Characterization and mechanical properties of coatings on magnesium by micro arc oxidation, Appl. Surf. Sci. 261 (2012) 774-782.

[7]N. Yamauchi, K. Demizu, N. Ueda, Friction and wear of DLC films on magnesium alloy, Surf. Coat. Technol. 193 (2005) 277-282.

[8]R.F. Zhang, S.F. Zhang, S.W. Duo, Influence of phytic acid concentration on coating properties obtained by MAO treatment on magnesium alloys, Appl. Surf. Sci. 255 (2009) 7893-7897.

[9]B.L. Jiang, D.J. Liu, Scientific aspects of restricting development and application of micro-arc oxidation technology, The Chinese Journal of Nonferrous Metals. 21 (2011), 2402-2407.

[10]A.L. Yerokhin, X. Nie, A. Leyland, A. Matthews and S. J. Dowey, Plasma electrolysis for surface engineering, Surf. Coat. Technol. 122 (1999) 73-93.

[11]C.B. Wei, X.B. Tian, S.Q. Yang, Anode current effects in plasma electrolytic oxidation, Surf. Coat. Technol. 201 (2007) 5021-5024.

[12]H. Yun, F. Gao, S. Durdu, A. Polat, M. Usta, A.H. Ucisik, H. Liang, Evaluation of microarc oxidized coatings on pure magnesium, Front. Appl. Plasma. Technol. 3 (2010) 40-44.

[13]G. J. Li, L. Li, C.Q. Xu, Research process of micro-arc oxidation ceramic coating on magnesium alloy, Hot Working Technology. 37 (2008) 94-97.

[14]A. Da Forno, M. Bestetti, Effect of the electrolytic solution composition on the performance of micro-arc anodic oxidation films formed on AM60B magnesium alloy, Surface and Coatings Technology. 205 (2010) 1783-1788. 
[15]L. Wang, L. Chen, Z.C. Yan, H.L. Wang, J.Z. Peng, The influence of additives on the stability behavior of electrolyte, discharges and PEO films characteristics, Journal of Alloys and Compounds. 493 (2010) 445-452.

[16]S.Y. Wang, Y.P. Xia, Microarc oxidation coating fabricated on AZ91D Mg alloy in an optimized dual electrolyte, Trans. Nonferrous Met. Soc. China. 23 (2013), 412-419.

[17]Y. Yang, H. Wu, Effect of current density on corrosion resistance of micro-arc oxide coatings on magnesium alloy, Trans. Nonferrous Met. Soc. China. 20 (2010) 688-692.

[18]R. Wang, Y.Z. Ma, M. Chen and Q.T. Tian, Micro-arc oxidation behavior of magnesium alloy at different voltage, Corrosion and Protection. 32 (2011) 363-365.

[19]J.R. Zhen, Y.C. Lu, Influencing factors of AZ91D magnesium alloy MAO film properties, Corrosion and Protection. 33 (2012) 567-570.

[20]Y. Ma, H. Zhan, Y.Z. My, W.L. Lv, J.Y. Feng and W. Gao, Effects of electrical parameters on microstructure and corrosion resistance of micro-arc oxidation coatings on AZ91D magnesium alloys, The Chinese Journal of Nonferrous Metals. 20 (2010) 1467-1473.

[21]S. Lu, L. Tang, X.Z. Jiang, Growth characteristic, microstructure and corrosion resistance of micro-arc oxidation coatings fabricated on ZK60 Mg alloy under two steps voltage-increasing mode, Advanced Materials Research. 337 (2011) 101-105.

[22]S. Lu, Z.X. Wang, J. Chen and X.S. Zhou, Optimization of dual electrolyte and characteristic of micro-arc oxidation coating fabricated on ZK60 Mg alloy, Trans. Nonferrous Met. Soc. China. 21 (2011), 929-935.

[23]Z.D. Liu, H. Fu, M.J. Sun, Z.Y. Zhang, Influence of negative voltage on coating of magnesium alloy micro-arc oxidation, Light Metals. (2009) 45-48.

[24]W. Han, Y.D. He, D.R. Wang, R.D. Xue, W. Gao, ZrO2-Y2O3 coating prepared by cathodic plasma electrolysis deposition, Chinese Journal of Rare Metals. 28(2004) 622-625.

[25]S.V. Gnedenkov, O.A. Khrisanfova, A.G. Zavidnaya, S.L. Sinebrukhov, P.S. Gordienko, Composition and adhesion of protective coatings on aluminum, Surface and Coatings Technology. 45(2001) 146-151.

[26]F. Peng, Technical study on micro-arc oxidation of magnesium alloy with different power supply modes, Lanzhou University of Technology, 2012, pp. 42. 